\title{
A Brief Overview of Amblyaudia
}

\author{
RaeLynn J. Lamminen, Daniel Houlihan \\ Minnesota State University, Mankato, USA \\ Email: daniel.houlihan@mnsu.edu
}

Received 29 April 2015; accepted 2 August 2015; published 5 August 2015

Copyright (C 2015 by authors and Scientific Research Publishing Inc.

This work is licensed under the Creative Commons Attribution International License (CC BY).

http://creativecommons.org/licenses/by/4.0/

(c) (i) Open Access

\begin{abstract}
Amblyaudia, a recent subcategory of auditory processing disorder, is characterized by asymmetrical auditory processing of an individual's ears. Amblyaudia can result in speech comprehension difficulties, reading difficulties, information processing deficits, and inattention. These difficulties can be mistakenly attributed to Attention Deficit Hyperactivity Disorder (ADHD), Specific Learning Disorders (SLD), depression, anxiety disorders, and communication disorders. Unfortunately, traditional hearing tests do not place the two ears in competition and cannot detect asymmetry. Therefore, students who exhibit these difficulties and have normal performance on traditional hearing tests should be also evaluated for amblyaudia with dichotic listening tests. Amblyaudia can be addressed through dichotic listening tasks that strengthen the non-dominant ear, as well as minor adjustments to the classroom environment. This paper will examine the current literature on amblyaudia and provide a brief overview of the causes, diagnosis, treatments, and prognosis.
\end{abstract}

\section{Keywords}

Amblyaudia, Auditory Processing Disorder, Otitis Media

\section{Introduction}

Amblyaudia is a new diagnostic category within Auditory Processing Disorders (APD) [1] [2]. When one ear is developmentally deprived it causes the other ear to compensate and leads to weaknesses in the listener's binaural processing of auditory information [2]-[4]. Children who experience temporary hearing loss, most commonly from ear infections, are at an increased risk of developing amblyaudia [5] [6]. Characteristics of amblyaudia include speech comprehension difficulties, reading difficulties, information processing deficits, poor verbal working memory, poor adaptive skills, and inattention [7] [8].

\section{Auditory Processing Disorders}

Children who perform below average on two different tests of auditory ability meet the criteria for an auditory 
processing disorder [9]. An auditory processing disorder is the breakdown in auditory abilities, such as auditory discrimination, binaural listening, and temporal processing, that can lead to the reduced acquisition of knowledge from auditory input. Auditory discrimination is the ability to process the frequencies, phonemes, words, and noise level present in acoustic input. Binaural listening is the ability to integrate, separate, and locate sources of acoustic input. Finally, temporal processing is the ability to resolve, integrate, and recognize patterns in the acoustic input [2]. Auditory processing disorder is estimated to affect between 2 and 5 percent of schoolaged children [10].

A recent diagnostic category of auditory processing disorder, amblyaudia, is characterized by an abnormally large performance discrepancy between the individual's two ears [11]. The asymmetrical processing abilities lead to weaknesses in the binaural processing of auditory information, much in the same way as lazy eye (amblyopia; [2]-[4]. Approximately 12 percent of children less than 5 years of age are at risk for amblyaudia [1] [2]. Of the individuals diagnosed with auditory processing disorder, 55 percent of them met diagnostic criteria for amblyaudia [5]. Therefore, children who are at risk for academic hearing difficulties should be screened for amblyaudia [5] [6].

\section{Testing and Assessment}

Amblyaudia cannot be identified by traditional hearing tests because there are no current tests that place the two ears in competition [1]. Instead, dichotic listening tests are used for screening and diagnosis because they put stress on the binaural auditory system and reveal any asymmetry between the auditory pathways [2] [5]. Some of the tests used are the Competing Words subtest of SCAN, staggered spondaic words test and the randomized dichotic digits test [1] [12]. Dichotic listening tests provide the listener with two monosyllabic words or digits simultaneously and is expected to repeat the words presented in each ear [13]. By placing the ears in competition, the child serves as his or her own control during testing [1]. Following testing, if the child has poor performance, he or she should be referred for further testing to rule out retrocochlear disorder, confirm the weaknesses, and receive a final diagnosis [2] [5]. The follow-up appointment can also rule out language and attention disorders if the dominant ear performs within normal range [1].

\section{Diagnosis}

The diagnosis of amblyaudia should address the nature of the processing weakness, which ear it affects, and the severity. Suggested severity criteria for amblyaudia is based off of interaural asymmetry. Borderline amblyaudia would have an interaural asymmetry of 10 - 19 percent, 20 - 29 percent would be the mild range, 30 - 39 percent would be moderate range, and 40 - 49 percent would be the moderately severe range. An interaural asymmetry of more than 50 percent would result in a severe amblyaudia diagnosis [5].

\section{Brain Physiology}

In order to fully understand the effects of amblyaudia on everyday life, conventional hearing must be explained. Sound waves are collected by the outer ear and sent inward for processing. As the sound waves reach the tympanic membrane, eardrum, they are converted into mechanical vibrations. They are then amplified by the malleus, incus, and stapes and transformed into fluid waves by the oval window. In the cochlea the timing information is enhanced for sound localization [14]-[16]. The input from both ears is then transferred through the trapezoid body and superior olivary complex. The superior olivary complex measures time difference and sound intensity. The output is then sent to the inferior colliculus for integration and routing of multi-modal sensory perception through the lateral lemniscus. The medial geniculate nucleus, located in the auditory thalamus, then relays frequency, intensity, and binaural information to the auditory cortex. The medial geniculate nucleus guides direction and maintenance of attention. The output is sent to the auditory cortex within the superior temporal gyrus. From the auditory cortex the information is sent to other cortical processing areas for further processing (e.g., Wernicke's) [14] [17]. From this we gather that monaural and binaural cues are initially processed separately prior to integration at the inferior colliculus [18] [19].

\section{Effects of Amblyaudia}

The auditory system of a child with amblyaudia compensates for the imbalanced inputs between ears by adjust- 
ing sensitivity to binaural spatial cues [18]. Because of this adjustment, amblyaudia is associated with degraded binaural spatial hearing and sound localization [20]. Binaural spatial hearing and sound localization play key roles in speech comprehension, especially in noisy environments. Difficulty with binaural spatial hearing may have secondary effects on educational development because of linguistic and cognitive difficulties [18] [21]. Linguistic difficulties result from the impairments in phonetic and phonological coding of sounds [6] [22] and articulation and syntax impairments [23]. Cognitive difficulties are closely related with linguistic difficulties. The misperception of some phonemes produces a poor semantic database, which affects reading fluency and comprehension [24] and can result in dyslexia [25]. Because of the difficulty segregating auditory information, amblyaudia has been linked to attention problems that can effect educational development [26]. Difficulties with adaptive skills and self-esteem have also been seen in children with amblyaudia [27].

Amblyaudia often presents with difficulties in attention, speech comprehension, and reading. Inattention, such as inconsistent response patterns and shorter attention spans, is common in children with amblyaudia. Additionally, speech comprehension is made difficult, especially within noisy environments, due to the decreased ability to localize sound, comprehend verbal material, and follow verbal directions with multiple steps [7] [18]. The deficits in speech comprehension also impact reading fluency and comprehension through a chain of reactions. The misperception of verbal phonemes leads to a poor semantic database, which then makes reading comprehension more tedious, decreases reading fluency, and increases the likelihood of dyslexia [8] [24].

\section{Causes}

Amblyaudia was initially thought to be a result of poor communication between the two hemispheres of the brain, however, more recent studies point to asymmetrical auditory input as the cause [28]. Asymmetrical auditory input during periods of auditory development leads to disruption in normal auditory development and results in neural impairment, which affects acoustic processing. Hearing loss is the primary disruption that leads to asymmetrical auditory input.

\subsection{Hearing Loss}

There are three types of hearing loss: Sensorineural, conductive, and mixed. Sensorineural hearing loss is related to nerve damage. This is commonly due to exposure to loud noise, head trauma, or inherited disorders [29]. Conductive hearing loss is experienced when sound waves are interrupted within the outer ear, tympanic membrane, or middle ear due to obstruction or malfunction [18]. Some causes of this type of hearing loss are earwax buildup, a ruptured eardrum and fluid accumulation. When hearing loss results from nerve damage as well as an obstruction or malfunction, it is referred to as mixed hearing loss [29]. The hearing loss associated with amblyaudia is conductive hearing loss. This is often due to fluid accumulation within the typically air-filled middle ear [2] [7] [18].

Conductive hearing loss reduces the listener's ability to segregate and locate sound sources as well as discriminate from interfering noises [30]-[32]. This is especially true with monaural hearing loss because the effects of hearing loss in one ear are typically more dramatic than those following hearing loss in both ears [7] [30] [33]-[38]. Additionally, hearing loss in one ear has profound effects on binaural spatial cues [18] [34]-[36] [39] [40].

\subsection{Otitis Media}

Amblyaudia has been correlated with early life auditory deprivation such as otitis media with prolonged periods of temporary hearing loss [2] [7] [18]. Approximately 89 percent of cases of otitis media presenting with conductive hearing loss resulted in amblyaudia [7]. During periods of temporary hearing loss, the auditory system is unable to fully manipulate acoustical input from the affected ear [18]. When temporary hearing loss occurs during early periods of auditory experience, the central auditory circuits that support sound location may be recalibrated [41]. These adaptations may be beneficial during the period of hearing loss, however, they often become maladaptive once normal hearing is restored [4] [38] [42]-[44]. Therefore, even after normal hearing has been restored there is a possibility of long lasting auditory perceptual deficits [4] [18].

Otitis media is an infection or dysfunction that leads to the accumulation of excess fluid in the middle ear cavity [7] [45]. The excess fluid can degrade the auditory signals transmitted to the brain [7]. Roughly 80 per- 
cent of children under the age of 3 experience otitis media making it the most commonly diagnosed illness among young children in the United States [7] [46] [47]. Approximately 75 percent of all infants have at least one episode during the first two years [48] [49] and 25 percent of infants develop recurrent or persistent otitis media [20]. Otitis media can often go undiagnosed given that it can occur without the presence of pain or infection [50].

\section{Treatment}

The processing difficulties of amblyaudia can be alleviated through interventions. Reducing the intensity of input to the dominant ear during dichotic listening tasks in order to strengthen the affected ear is usually the first part of the intervention. Then systematically increase the intensity to the dominant ear as long as the affected ear's performance remains high. This should be continued until both ears can perform more equivalently during dichotic listening tasks at equal intensity [2]. Another option is a short-term intervention program called Auditory Rehabilitation for Interaural Asymmetry (ARIA), which follows a similar progression [51].

\section{Prognosis}

The timing and duration of hearing loss both play key roles in the severity and prognosis of amblyaudia [18]. Abnormal acoustical experience during critical periods of development can produce profound changes in neuronal sensitivity [4] [38] [42]-[44]. These changes may help during the period of hearing loss but may be maladaptive once normal auditory inputs are available [52] [53]. Compensating for the reductions in the quality of input during those periods of development can be difficult [54] [55]. There is mixed research regarding when the changes in neuronal sensitivity dissipate. Some studies say that impairments are long lasting even after normal hearing has returned [7] [41] [56] [57]. However, other studies say that deficits largely disappear after a few years of typical auditory experience [20] [50] [58] [59]. Even if amblyaudia resolves by late childhood, there is no way to determine where the child would be without the period of asymmetrical hearing [7]. Additionally, it is hard to determine whether or not the individual will experience ripple effects on linguistic, cognitive, and social functions developed during the periods of atypical hearing.

\section{Impact on School Psychologists}

School psychologists should be aware of amblyaudia given that the symptoms can resemble other common disorders and traditional hearing tests do not screen for it. Children with amblyaudia can have problems with attention, reading, and speech. Amblyaudia has the potential to be misdiagnosed as Attention Deficit Hyperactivity Disorder (ADHD), a Specific Learning Disorder (SLD), Depression, an Anxiety Disorder, and a Communication Disorder [48]. Awareness is important because an accurate diagnosis means proper treatment. While the assistance provided for the other disorders would address the symptoms of amblyaudia, strengthening the nondominant ear would address the cause.

While the non-dominant ear is being strengthened, adjustments to the classroom environment can set the child up for greater success. Directions and academic instructions should be given while facing the students instead of the board. Directions should be given with only one or two steps and should also be provided visually (i.e., written on the board). After academic instructions or directions are given, additional processing time should be allowed. The seating location of the student also plays a role in his or her ability to listen. Seat the child away from common sources of noise (i.e., air conditioner, window, door) as well as close to the board. Additional care should be taken in order to minimize classroom noise and distractions as much as possible. Finally, a private hand signal can go a long way for a student to communicate with the teacher about frustration or the need for assistance [60].

\section{Conclusion}

Difficulties in attention, speech comprehension, and reading can increase frustration as well as make processing information more challenging. Special attention should be given to students who exhibit similar difficulties and show normal performance on traditional hearing tests. A correct diagnosis of amblyaudia can lead to interventions that address the asymmetrical auditory input and alleviate some of the symptoms. Amblyaudia can be addressed by strengthening the non-dominant ear through dichotic listening tasks. Additionally, small adjustments to classroom seating and the way information is presented can set the child up for greater academic success. 


\section{References}

[1] Beck, D.L. (Interviewer) and Moncrieff, D.W. (Interviewee) (2010) Amblyaudia and Auditory Processing Disorders: Interview with Debbie Moncrieff, PhD. [Interview transcript]. Retrieved from American Academy of Audiology Web Site. http://www.audiology.org/news/amblyaudia-and-auditory-processing-disorders-interview-debbie-moncrieff-phd

[2] Moncrieff, D.W. (2012) Amblyaudia: Diagnosis and Treatment of a Specific Type of APD [PowerPoint Slides]. https://www.paaudiology.org/Convention/2012/presentations/Amblyaudia_Presentation_for_PAA_2012-Moncrieff

[3] Moncrieff, D.W. (2006) Identification of Binaural Integration Deficits in Children with the Competing Words Subtest: Standard Score versus Interaural Asymmetry. International Journal of Audiology, 45, 546-558. http://dx.doi.org/10.1080/10503300500485631

[4] Popescu, M.V. and Polley, D.B. (2010) Monaural Deprivation Disrupts Development of Binaural Selectivity in Auditory Midbrain and Cortex. Neuron, 65, 718-731. http://dx.doi.org/10.1016/j.neuron.2010.02.019

[5] Moncrieff, D.W., Demarest, B.S., Mormer, E.R. and Littlepage, R. (2014) Prevalence and Severity of Auditory Processing Deficits in Adjudicated Adolescents Screened with Dichotic Listening Tests: Implications for Diagnosis and Intervention. Seminars in Hearing, 35, 39-49. http://dx.doi.org/10.1055/s-0033-1363523

[6] Uclés, P., Alonso, M.F., Aznar, E. and Lapresta, C. (2012) Clinical Study: The Importance of Right Otitis Media in Childhood Language Disorders. International Journal of Otolaryngology, 2012, 1-10. http://dx.doi.org/10.1155/2012/818927

[7] Whitton, J.P. and Polley, D.B. (2011) Evaluating the Perceptual and Pathophyisological Consequences of Auditory Deprivation in Early Postnatal Life: A Comparison of Basic and Clinical Studies. Journal of the Association for Research in Otolaryngology, 12, 535-546. http://dx.doi.org/10.1007/s10162-011-0271-6

[8] Moncrieff, D.W., Jerger, J., Wambacq, I., Greenwald, R. and Black, J. (2004) ERP Evidence of a Dichotic Left-Ear Deficit in Some Dyslexic Children. Journal of Academic Audiology, 15, 518-534. http://dx.doi.org/10.3766/jaaa.15.7.6

[9] Moncrieff, D.W., Jorgensen, L. and Ortmann, A. (2013) Psychophysical Auditory Tests. In: Celesia, G.G., Ed., Handbook of Clinical Neurophysiology: Disorders of Peripheral and Central Auditory Processing, Elsevier B.V., Amsterdam, 217-234. http://dx.doi.org/10.1016/B978-0-7020-5310-8.00011-9

[10] Whitelaw, M. (2011) Auditory Processing Disorders in Children: Beyond the Audiogram [PowerPoint Slides]. https://www.audiologyonline.com/articles/auditory-processing-disorders-in-children-11227-11227

[11] Moncrieff, D.W. (2010) Amblyaudia: Evidence of Indistinct Processing of Auditory Information in Children. Proceedings of the American Auditory Society Annual Meeting, Scottsdale, March 2010.

[12] Jerger, J., Jerger, S. and Pirozzolo, F. (1991) Correlational Analysis of Speech Audiometric Scores, Hearing Loss, Age, and Cognitive Abilities in the Elderly. Ear and Hearing, 12, 103-109. http://dx.doi.org/10.1097/00003446-199104000-00004

[13] Keith, R.W. (2008) SCAN-C Test for Auditory Processing Disorders in Children—Revised: Technical Report. Pearson Education, Upper Saddle River.

[14] Hersh, M.A. and Johnson, M.A. (2003) Assistive Technology for the Hearing-Impaired, Deaf, and Blind. Springer Publishing Company, New York. http://dx.doi.org/10.1007/b97528

[15] Martini, F.H., Ober, W.C. and Nath, J. L. (2011) Visual Anatomy \& Physiology. Pearson Education, New York.

[16] Silverthorn, D.U. (2007) Human Physiology: An Integrated Approach. 4th Edition, Benjamin Cummings, San Francisco.

[17] Purves, D., Fitzpatrick, D., Katz, L.C., Lamantia, A.S., McNamara, J.O., Williams, S.M. and Augustine, G.J. (2001) Neuroscience. 2nd Edition, Sinauer Associates, Inc., Sunderland.

[18] Keating, P. and King, A.J. (2013) Developmental Plasticity of Spatial Hearing Following Asymmetric Hearing Loss: Context-Dependent Cue Integration and Its Clinical Implications. Frontiers in Systems Neuroscience, 7, 1-20. http://dx.doi.org/10.3389/fnsys.2013.00123

[19] Young, E.D., Spirou, G.A., Rice, J.J. and Voigt, H.F. (1992) Neural Organization and Responses to Complex Stimuli in the Dorsal Cochlear Nucleus. Philosophical Transactions of the Royal Society of London, Series B: Biological Sciences, 336, 407-413. http://dx.doi.org/10.1098/rstb.1992.0076

[20] Hall, J.W., Grose, J.H. and Pillsbury, H.C. (1995) Long-Term Effects of Chronic Otitis Media on Binaural Hearing in Children. Archives of Otolaryngology Head and Neck Surgery, 121, 847-852. http://dx.doi.org/10.1001/archotol.1995.01890080017003

[21] Lenneberg, E. (1975) The Biological Foundation of Language. Alianza, Madrid.

[22] Stelmachowicz, P.G., Kopun, J., Mace, A., Lewis, D.E. and Nittrouer, S. (1995) The Perception of Amplified Speech by Listeners with Hearing Loss: Acoustic Correlates. Journal of the Acoustical Society of America, 98, 1388-1399. http://dx.doi.org/10.1121/1.413474 
[23] Menyuk, P. (1980) Effect of Persistent Otitis Media on Language Development. Annals of Otology, Rhinology and Laryngology, 89, 257-263.

[24] Moore, D.R. (2007) Auditory Processing Disorders: Acquisition and Treatment. Journal of Communication Disorders, 40, 295-304. http://dx.doi.org/10.1016/j.jcomdis.2007.03.005

[25] Moncrieff, D.W. (2004) Identification of Binaural Integration Deficits in Children with the Competing Words Subtest: Standard Score versus Interaural Asymmetry. International Journal of Audiology, 45, 200-207. http://dx.doi.org/10.1080/10503300500485631

[26] Roberts, J.E., Burchinal, M.F., Collier, A.M., Ramey, C.T., Koch, M.A. and Henderson, F.W. (1989) Otitis Media in Early Childhood and Cognitive, Academic, and Classroom Performance of the School-Aged Child. Pediatrics, 83, 477-485.

[27] Kreisman, N.V., John, A.B., Kreisman, B.M., Hall, J.W. and Crandell, C.C. (2012) Psychosocial Status of Children with Auditory Processing Disorder. Journal of the American Academy of Audiology, 23, 222-233. http://dx.doi.org/10.3766/jaaa.23.3.8

[28] Musiek, F.E. and Weihing, J. (2011) Perspectives on Dichotic Listening and the Corpus Callosum. Brain and Cognition, 76, 225-232. http://dx.doi.org/10.1016/j.bandc.2011.03.011

[29] Dobie, R.A. and Van Hemel, S. (2004) Hearing Loss: Determining Eligibility for Social Security Benefits. National Academies Press, Washington, DC.

[30] Clements, M. and Kelly, J.B. (1978) Auditory Spatial Responses of Young Guinea Pigs (Cavia porcellus) during and after Ear Blocking. Journal of Comparative and Physiological Psychology, 92, 34-44. http://dx.doi.org/10.1037/h0077424

[31] Moore, D.R., Hine, J.E., Jiang, Z.D., Matsuda, H., Parsons, C.H. and King, A.J. (1999) Conductive Hearing Loss Produces a Reversible Binaural Hearing Impairment. Journal of Neuroscience, 19, 8704-8711.

[32] Xu, H., Kotak, V.C. and Sanes, D.H. (2007) Conductive Hearing Loss Disrupts Synaptic and Spike Adaptation in Developing Auditory Cortex. Journal of Neuroscience, 27, 9417-9426. http://dx.doi.org/10.1523/JNEUROSCI.1992-07.2007

[33] Moore, D.R. (2002) Auditory Development and the Role of Experience. British Medical Bulletin, 63, 171-181. http://dx.doi.org/10.1093/bmb/63.1.171

[34] Kumpik, D.P., Kacelnik, O. and King, A.J. (2010) Adaptive Reweighting of Auditory Localization Cues in Response to Chronic Unilateral Earplugging in Humans. Journal of Neuroscience, 30, 4883-4894. http://dx.doi.org/10.1523/JNEUROSCI.5488-09.2010

[35] Lupo, J.E., Koka, K., Thornton, J.L. and Tollin, D.J. (2010) The Effects of Experimentally Induced Conductive Hearing Loss on Spectral and Temporal Aspects of Sound Transmission through the Ear. Hearing Research, 272, 30-41. http://dx.doi.org/10.1016/j.heares.2010.11.003

[36] Moore, D.R., Hutchings, M.E., King, A.J. and Kowalchuk, N.E. (1989) Auditory Brain Stem of the Ferret: Some Effects of Rearing with a Unilateral Earplug on the Cochlea, Cochlear Nucleus, and Projections to the Inferior Colliculus. Journal of Neuroscience, 9, 1213-1222.

[37] Polley, D.B., Thompson, J.H. and Guo, W. (2013) Brief Hearing Loss Disrupts Binaural Integration during Two Early Critical Periods of Auditory Cortex Development. Nature Communications, 4, 2547. http://dx.doi.org/10.1038/ncomms3547

[38] Silverman, M.S. and Clopton, B.M. (1977) Plasticity of Binaural Interaction I: Effect of Early Auditory Deprivation. Journal of Neurophysiology, 40, 1266-1274.

[39] Blauert, J. (1997) Spatial Hearing: The Psychophysics of Human Sound Localization. MIT Press, Cambridge.

[40] Moore, D.R., Hartley, D.E. and Hogan, S.C. (2003) Effects of Otitis Media with Effusion (OME) on Central Auditory Function. International Journal of Pediatric Otorhinolaryngology, 67, S63-S67. http://dx.doi.org/10.1016/j.ijporl.2003.08.015

[41] Schreiner, C.E. and Polley, D.B. (2014) Auditory Map Plasticity: Diversity in Causes and Consequences. Current Opinion in Neurobiology, 24, 143-156. http://dx.doi.org/10.1016/j.conb.2013.11.009

[42] Brugge, J.F., Orman, S.S., Coleman, J.R., Chan, J.C. and Phillips, D.P. (1985) Binaural Interactions in Cortical Area AI of Cats Reared with Unilateral Atresia of the External Ear Canal. Hearing Research, 20, 275-287. http://dx.doi.org/10.1016/0378-5955(85)90032-2

[43] Clopton, B.M. and Silverman, M.S. (1977) Plasticity of Binaural Interaction II: Critical Period and Changes in Midline Response. Journal of Neurophysiology, 40, 1275-1280.

[44] Moore, D.R. and Irvine, D.R. (1981) Plasticity of Binaural Interaction in the Cat Inferior Colliculus. Brain Research, 208, 198-202. http://dx.doi.org/10.1016/0006-8993(81)90632-6 
[45] Werner, L.A. and Ward, J.H. (1997) The Effect of Otitis Media with Effusion on Infants' Detection of Sound. Infant Behavior and Development, 20, 275-279. http://dx.doi.org/10.1016/S0163-6383(97)90030-8

[46] Engel, J., Anteunis, L., Volovics, A., Hendriks, J. and Marres, E. (1999) Prevalence Rates of Otitis Media with Effusion from 0 to 2 Years of Age: Healthy-Born versus High-Risk-Born Infants. International Journal of Pediatric Otorhinolaryngology, 47, 243-251. http://dx.doi.org/10.1016/S0165-5876(98)00185-2

[47] Lanphear, B.P., Byrd, R.S., Auinger, P. and Hall, C.B. (1997) Increasing Prevalence of Recurrent Otitis Media among Children in the United States. Pediatrics, 99, 318-333. http://dx.doi.org/10.1542/peds.99.3.e1

[48] American Psychiatric Association (2013) Diagnostic and Statistical Manual of Mental Disorders. 5th Edition, American Psychiatric Association, Washington, DC.

[49] Gravel, J.S., McCarton, C.M. and Ruben, R.J. (1988) A Prospective Study of Otitis Media in Infants Born at Very Low Birthweight. Acta Otolaryngologica, 106, 516-521. http://dx.doi.org/10.3109/00016488809119512

[50] Gravel, J.S. and Wallace, I.F. (2000) Effects of Otitis Media with Effusion on Hearing in the First 3 Years of Life. Journal of Speech, Language, and Hearing Research, 43, 631-644. http://dx.doi.org/10.1044/jslhr.4303.631

[51] Moncrieff, D.W. and Wertz, D. (2008) Auditory Rehabilitation for Interaural Asymmetry: Preliminary Evidence of Improved Dichotic Listening Performance Following Intensive Training. International Journal of Audiology, 47, 84-97. http://dx.doi.org/10.1080/14992020701770835

[52] Gold, J.I. and Knudsen, E.I. (2000) A Site of Auditory Experience-Dependent Plasticity in the Neural Representation of Auditory Space in the Barn Owl's Inferior Colliculus. Journal of Neuroscience, 20, 3469-3486.

[53] Keating, P., Dahmen, J.C. and King, A.J. (2013) Context-Specific Reweighting of Auditory Spatial Cues Following Altered Experience during Development. Current Biology, 23, 1291-1299. http://dx.doi.org/10.1016/j.cub.2013.05.045

[54] Zumach, A., Chenault, M.N., Anteunis, L. and Gerrits, E. (2010) Speech Perception after Early-Life Otitis Media with Fluctuating Hearing Loss. Audiology and Neurotology, 16, 304-314. http://dx.doi.org/10.1159/000322501

[55] Zumach, A., Gerrits, E., Chenault, M. and Anteunis, L. (2010) Long-Term Effects of Early-Life Otitis Media on Language Development. Journal of Speech, Language, and Hearing Research, 53, 34-43. http://dx.doi.org/10.1044/1092-4388(2009/08-0250)

[56] Hogan, S.C. and Moore, D.R. (2003) Impaired Binaural Hearing in Children Produced by a Threshold Level of Middle Ear Disease. Journal of the Association for Research in Otolaryngology, 4, 123-129. http://dx.doi.org/10.1007/s10162-002-3007-9

[57] Moore, D.R., Hutchings, M.E. and Meyer, S.E. (1991) Binaural Masking Level Differences in Children with a History of Otitis Media. Audiology, 30, 91-101. http://dx.doi.org/10.3109/00206099109072874

[58] Gravel, J.S., Roberts, J.E., Roush, J., Grose, J., Besing, J., Burchinal, M. and Zeisel, S. (2006) Early Otitis Media with Effusion, Hearing Loss, and Auditory Processes at School Age. Ear and Hearing, 27, 353-368. http://dx.doi.org/10.1097/01.aud.0000224727.45342.e9

[59] Roberts, J.E., Burchinal, M.R., Davis, B.P., Collier, A.M. and Henderson, F.W. (1991) Otitis Media in Early Childhood and Later Language. Journal of Speech and Hearing Research, 34, 1158-1168. http://dx.doi.org/10.1044/jshr.3405.1158

[60] (2014) Accommodations for Students with Learning Disabilities. http://www.ncld.org/students-disabilities/accommodations-education/accommodations-students-learning-disabilities 